\title{
Homemade Mask: How To Protect Ourselves From Microorganisms?
}

\author{
Bianca Pizzorno Backx* \\ UNIVERSIDADE FEDERAL DO RIO DE JANEIRO, Campus Duque de Caxias Professor Geraldo Cidade, Rodovia Washington Luiz (BR-040) Km \\ 104,5 - Santa Cruz da Serra, Duque de Caxias / RJ, Brazil
}

*Corresponding author: Bianca Pizzorno Backx. UNIVERSIDADE FEDERAL DO RIO DE JANEIRO, Campus Duque de Caxias Professor Geraldo Cidade, Rodovia Washington Luiz (BR-040) Km 104,5 - Santa Cruz da Serra, Duque de Caxias / RJ, Brazil

\begin{abstract}
A threat is taking over the world today. SARS-CoV-2 is a virus that spread throughout the planet, behaviorally changing world society. Humanity seeks alternatives to increase the physical barrier associated with the protection of homemade masks.Viruses, which have a semantic origin in the Latin, "toxin" or "poisonous", are infectious agents that mostly assume a nanometric scale, with a size around 20-300 nm in diameter.An abiotic material, capable of inhibiting the spread of viruses is indispensable. Understanding the virus's adhesion to the surface of the textile is very important for the choice of the best tissue, which has less adhesion of the virus to the surface. This minimization of virus adhesion can be promoted by the modification of surface characteristics of the textiles. The addition of nanostructures is capable of presenting antimicrobial activity, an essential factor for obtaining efficient textiles for making homemade masks.
\end{abstract}

Keyword: Homemade mask, Microorganisms, Textiles, Covid-19, Supramolecular interactions

\section{Introduction}

The nanometer is equivalent to 1 billionth of a meter, $10^{-9} \mathrm{~m}$. The formation of nanoparticles occurs with a large proportion of their atoms found on the surface compared to the innermost layers. Nanoparticles have a larger surface area per unit mass compared to larger particles [1]. Since chemical reactions occur on surfaces, it means that nanoparticles are extremely more reactive. Electrostatic stabilization occurs when the repulsive forces exceed Van der Waals forces [2]. This understanding is based on the forces of supramolecular interactions [3]. The viral action of nanoparticles has been widely explored. Silver nanoparticles, for example, have broad antiviral effects for herpes simplex viruses (HSV), human immunodeficiency viruses (HIV), Hepatitis B virus (HBV), among others [4]. AgNPs have efficient, eco-friendly synthesis routes. The antiviral properties of nanoparticles can involve interaction with nucleic acids or thiol groups of proteins. For metallic nanoparticles with antimicrobial action, already established in the literature, such as, for example, silver nanoparticles (AgNPs), gold nanoparticles (AuNPs), zinc oxide nanoparticles (ZnNPs), oxide copper nanoparticles ( $\mathrm{Cu}_{2} \mathrm{ONPs}$ ) have different synthesis routes [5]. Bacteria, fungi, and viruses are of concern to society around the world. Many studies are based on the ability of new materials to have an antimicrobial action. Supramolecular systems are nanostructured organizations able to act between nanostructures and microorganisms. It can be possible due to their high reactivity and equivalent size [6]. The SARS-CoV-2 viral particle size is around 70 to $90 \mathrm{~nm}$ [7]. Interaction between nanoparticles and viral particles is efficient because, through efficient interactions, nanostructures' action is efficient. The interaction between the virus and the adhesion surface is based on intermolecular interactions [8]. The nanoparticles synthesized by the green route have interactions between the dispersive medium.

Supramolecular chemistry is the basis of green systems. Able to stabilize nanostructures in extracts of plant origin. The search for antimicrobial action associated with nanoparticles is an essential initiative associated with the low cost, low concentration of precursor, and almost no environmental impact. Microorganisms, 
such as viruses, fungi, and bacteria, are often pathogenic and can cause severe infections in humans, animals, or plants. Thus, there is a growing need to seek new antimicrobial agents of natural and non-toxic origin [9]. Viruses do not have an autonomous life, requiring host cells to replicate their genetic material, RNA, or DNA and guarantee their survival by producing new viral particles [10]. Studies at the University of Southampton, England, revealed the virus's surface characteristics that caused COVID-19. There are many proteins on its surface, which are used to connect and penetrate our cells. In general, they are disguised with sugar-coated spikes, known as glycans, that help the virus escape the human immune system [11]. Associating the understanding of adhesion of the viral particle to different textiles is a primary focus of study. Due to the immense variation in the composition of the fabrics, some are mostly composed of natural fibers. Others are compositions of natural and synthetic fibers, and others called non-woven fabrics are formed by synthetic fibers chemical binders bond the fibers or non-woven filaments. For such a wide range of textile compositions, understanding the supramolecular interactions capable of increasing virus adhesion or even repelling them is essential. Understanding whether the viral particle will have more exceptional adhesion to natural, synthetic fiber fabrics and whether this adhesion is permanent is of great interest. There is a possibility that a textile composition is sufficiently capable of repelling the virus. In cases where the virus tends to adhere, having textile with nanostructures capable of making it antimicrobial is of immense advantage [12-16].

\section{Conclusion}

Studies should be developed to understand the virus and textiles' adhesion. It is essential to understand the protection of physical barriers associated with the textiles' interstice sizes and hydrophobicity of the surface of textiles. The adhesion of viral particles also can be minimized by the quality of the textiles' fiber. Besides, antimicrobial textiles with the addition of nanoparticles that have antimicrobial activity should be extensively studied to be potentially used to minimize contamination by the virus that causes COVID-19 and other diseases associated with microorganisms.

\section{References}

1. Linic S, Aslam U, Boerigter C, Morabito M (2015) Photochemical transformations on plasmonic metal nanoparticles. Nat Mater 14: 567576.
2. Cai W, Xiao C, Qian L, Cui Shuxun (2018) Detecting van der Waals forces between a single polymer repeating unit and a solid surface in high vacuum. Nano Research 12: 57-61.

3. Backx BP (2020) The Influence of Supramolecular Systems on Antimicrobial Action. Scientific Journal of Technical and Biomedical Research.

4. Galdiero S, Falanga A, Vitiello M, Cantisani M, Marra V, et al. (2011) Silver nanoparticles as potential antiviral agents. Molecules 16(10): 88948918.

5. Łoczechin A, Séron K, Barras A, Giovanelli E, Belouzard S Chen, et al. (2019) Functional Carbon Quantum Dots as Medical Countermeasures to Human Coronavirus. ACS Applied Materials and Interfaces 11(46): 42964-42974

6. Patel V, Berthold D, Puranik P, Gantar M (2015) Screening of cyanobacteria and microalgae for their ability to synthesize silver nanoparticles with antibacterial activity. Biotech Rep 5: 112-119.

7. Kim JM, Chung YS, Jo HJ (2020) Identification of Coronavirus Isolated from a Patient in Korea with COVID-19. Osong Public Health Res Perspect 11(1): 3-7.

8. Antunes Filho S, dos Santos OAL, dos Santos MS, Backx BP (2020) Exploiting Nanotechnology to Target Viruses. J Nanotechnol Nanomaterials 1(1): 11-15.

9. Syafiuddin A, Salmiati S, Salim MR, et al. (2017) A review of silver nanoparticles Researchers trends, global consumption, synthesis, properties, and future challenges. J Chin Chem Soc 64(7): 732-756.

10. Singh L., Kruger HG, Maguire GE, Govender T, Parboosing R (2017) The role of nanotechnology in the treatment of viral infections. Therapeutic advances in infectious disease 4(4): 105-131.

11. Yasunori Watanabe, Joel D Allen, Daniel Wrapp, Jason S McLellan, Max Crispin (2020) Site-specific analysis of the SARS-CoV-2 glycan shield.

12. Backx B, Delazare T (2019) The influence of the dispersive medium on efficient and eco-friendly synthesis of silver nanoparticles for application in antimicrobial fabric. Revista Verde de Agroecologia e esenvolvimento Sustentável 14(2): 252-257.

13. Backx BP, Pedrosa BR, Delazare T, Fernanda Ribeiro Do Carmo Damasceno, Otávio Augusto Leitão Dos Santos (2018) Green synthesis of silver nanoparticles: A study of the dispersive efficiency and antimicrobial potential of the extracts of Plinia cauliflora for application in smart textiles materials for healthcare. J Nanomater MolNanotechnol 7:1-10.

14. Khan I M, Ahmad A, Miyan L, Ahmad M, Aziz N (2017) Synthesis of charge transfer complex of chloranilic acid as an acceptor with p-nitroaniline as a donor: Crystallographic, UV-visible spectrophotometric and antimicrobials. J Mol Struct 1141: 687-697.

15. Lara HH, Garza Trevino EN, Ixtepan-Turrent L, Nam Joo Lee, Mee Seon Kim, et al. (2011) Silver nanoparticles are broad-spectrum bactericidal and virucidal compounds. J Nanobiotech 9: 30.

16. Prasad R, Pandey R, Barman I (2016) Engineering tailored nanoparticles with microbes: quo Vadis? WIREs. Nanomed Nanobiotechnol 8: 316330. 
(C) (P) This work is licensed under Creative

To Submit Your Article Click Here: $\quad$ Submit Article

DOI: $10.32474 /$ MAMS.2020.03.000159

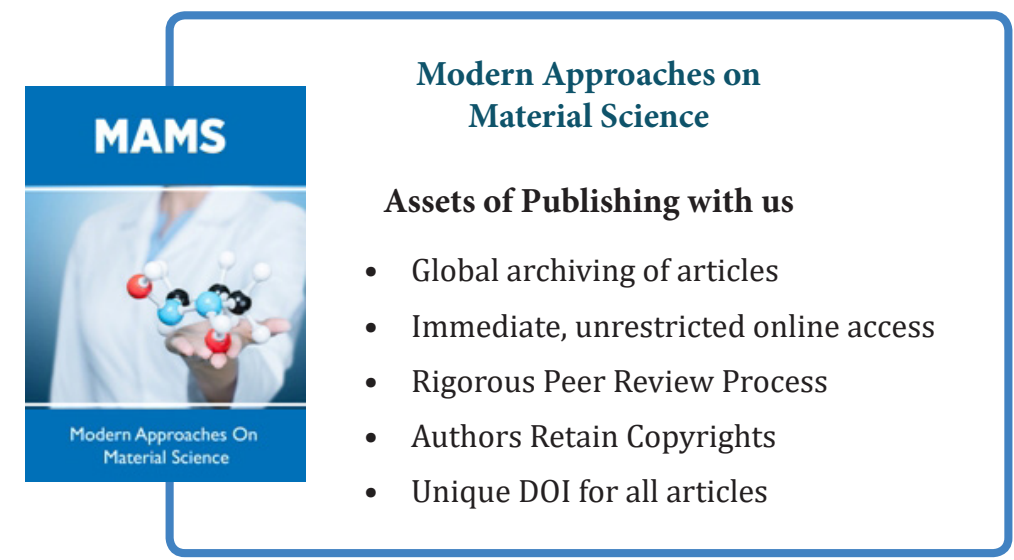

